\title{
An Empirical Analysis on the Changes of Students' Learning Behaviors Based on Online Presentation- Assimilation-Discussion Mode
}

\author{
Ming $\mathrm{Cao}^{1,2,{ }^{*}}$ and Xiangfu Fan ${ }^{2}$ \\ ${ }^{1}$ School of Humanity and International Education, Xi' an Peihua University, Xi'an 710125, China \\ ${ }^{2}$ School of International Education and Humanities, Xi'an Kedagaoxin University, Xi' 'an710109, China \\ *Corresponding author.Email: caoming@peihua.edu.cn
}

\begin{abstract}
Online Presentation-Assimilation-Discussion (OPAD) is a new type of internet-based teaching mode. The purpose of this paper is to study students online learning behaviors based on OPAD mode. It mainly focuses on how students' feelings and attitudes toward the online learning influence their learning behaviors. The quality of teaching design has also been tested in several internet platforms, including QQ, LanMuo Cloud Class and Wechat. A quasi-experimental study sampled 32 English major students as an experimental group and 30 as a control group from freshmen of an ordinary college in three-month online Integrated English Course teaching. By using T-test, correlation, and regression of SPSS 26.0, statistics show that learning behavior changes have a higher level of correlation with students' feelings, attitudes and teaching design, while teaching design and students' attitudes have played crucial roles. As a result, interactive teaching design in OPAD turns out to be an effective mode to the changes of students' online learning behaviors.
\end{abstract}

Keywords: OPAD mode interaction, students' learning behaviors, teaching design, attitudes

\section{INTRODUCTION}

Along with the normalization of online and online-offline combination teaching and learning, implementing effective internet-based teaching has become a new challenge for college teachers and students. Recent research showed that more than $70 \%$ students had a good perception of the application toward online learning [1-2]. But other research found that students dropped off the online course just because they felt lonely facing computer by themselves [3]. The reason may include the facts that the internet-based learning has less support from teachers and the individual student cannot perceive the rate of progress from peers. As a result, the online learning engagement depends on not only students' self control, but also how teachers support student learning. As behavioral engagement involves students participating in activities, and a survey showed that more than one third students found discussion to be the most preference as an engaging activity in an online course [4], paying attention to teacher-student and student-student interaction apparently turns to be a good idea to strengthen online learning. A current research also showed that multidimensional interaction design supported a good learning result when combining with multi-media platform in online learning [5].

Despite the above result, teachers still face challenges when teaching online. For example, some students feel hard to fully involve into the online class [1]; the assignment completion shows that some students cannot catch up the pace of online learning [4]; the effectiveness of online course is less than offline course in certain aspects [6]. To solve these problems, this paper used Presentation-Assimilation-Discussion (PAD) mode to strengthen discussion. It is known that PAD mode has achieved primary results in many subjects [7-8]. The main function is to focus on teacher-student and student-student interaction. Therefore, we use this mode and try to answer the following questions: How does this new mode in online situation bring about actual changes for students' learning behaviors under the constraint of time and location? What are students' feelings when they attend Online Presentation-Assimilation-Discussion (OPAD) mode English course? As English teaching and learning highly relies on interactions, whether OPAD class teaching design with frequent discussions provides a new path for implementing student-centred online learning?

\section{INTERACTION AND LEARNING BEHAVIOR}

Language teaching has its own special requirements. Teachers' expression, explanation, students' practice, imitation are highly related to interaction. Theoretically, a variety of network platforms can provide us with another space to imagine. Using pictures, text, sound, light, images, and other information to carry out a variety of forms of communication, teachers and students can focus on the interaction of information, and even avoid some meaningless interference of offline interaction. Therefore, 
teacher-student and student-student interaction play a key role in online English teaching and learning.

\subsection{About Interaction}

Interaction is a process in which two or more people exchange thoughts and feelings, transmit information, and have an impact on both sides. Moore had a clear classification of interaction, namely the student-teacher interaction, student-student interaction, and student-content interaction. Teacher-student interaction is based on the teacher's hypothesis of how much of the material the students have grasped. Student-student interaction is based on the concept of equality in which students feel free to discuss concepts and what they have understood with their peers when teachers and authority figures are absent. Student-content interaction has been understood to be a unique interaction between students and the content they are learning, including how students understand the learning materials, the concepts from material, and the cognitive structure in students' minds. This dialogue may also be known as 'an internal monologue' [9]. Mehall argues that interaction of online courses should be designed for purposeful interpersonal interaction, including purposeful instructional interaction, social interaction, and support interaction [10]. This may make up the lost of offline interaction in which the teacher is easy to capture students' learning signals. Other scholars study that group discussion can enhance the interaction between students and enhance students' understanding of learning materials $[4,11]$. With the development of network technology, online interaction on multiple network platforms has expanded the scope of understanding of the concept of interaction. Therefore, the expression of "multidimensional interaction" has also been favoured by some

\subsection{Learning Behavior}

Learning behavior is the result of the interaction between the learning subject and the surrounding social environment. Online learning behaviors mainly include frequency of login, duration of study, communication and discussion, resource browsing, post volume and so on. Li and Wei believe that communication and collaboration is the most important factor affecting learners' online learning behaviors [12]. An investigation of Xiong and $\mathrm{Wu}$ focuses on students' online learning on the aspects of pressures on sensory organs, learning attitude, and the way of interaction with teachers [13]. These emphasize that friendly companionship, interactive teaching mode and other supportive methods benefit students' online learning. Apparently, to achieve similar results of online teaching to offline teaching, students need to be supported in many aspects. Teachers not only need to be familiar with the teaching platform, pay attention to teaching design, but also need to select an appropriate teaching mode to match online teaching and learning. PAD mode, which focuses on discussion between the teacher and students, and students and students, turns to fit it well. Whether it has a positive impact on students and how it influences students' learning behaviors are one of the main tasks of this study. We select user friendly network platforms such as, QQ, Lanmuo Cloud Class and WeChat as the representative of the platforms to practice.

\section{ONLINE INSTRUCTIONAL DESIGNS UNDER OPAD MODE}

Teacher's presentation, students' independent learning and discussion are the basic processes of the PAD mode. As the QQ platform is the most frequently-used platform, both teachers and students can use it to perform many tasks such as, lecturing, group discussion, conference, for example. Lanmuo cloud class platform can realize many interactive functions, such as light live broadcasting, discussion, urgent answer, brainstorming, group cooperation, voting, questionnaire, presentation, debate, testing, etc. WeChat platform is flexible and easy to be handled for extra teacher-student interaction. These three platforms are good enough to support the basic process of the OPAD mode. Therefore, taking Integrated English course as an example, PAD mode design has been implemented for online interaction during teaching and learning.

\subsection{PAD Mode}

PAD mode is a new teaching paradigm initiated by Zhang Xuexin of Fudan University, China, in 2014[7]. It divides the class time into two parts, half of which is for teachers to teach and the other half is for students to discuss. PAD class is consisted of three distinct processes, namely Presentation, Assimilation and Discussion. In offline teaching, these three processes have been validated through different subjects, and within the processes, interaction is the key. There are two paths of learning, In-class PAD and Between-class PAD. In In-class PAD, students are arranged to review the contents for normally 10-15 minutes right after teacher's presentation, and then have a discussion with peers. Through student-student interaction, some concerns or confusions are clarified. Difficult questions are solved under the help of the teacher, which leads teacher-students interaction in the class. While Between-class PAD applies another path to study. After the teacher's presentation, students often review the main points after class, which calls internalization process. Through self-learning, they have mastered the basic knowledge the teacher taught. Questions or concerns are also discussed with group members. Same as In-class PAD, students bring questions they cannot solve to seek for teacher's help through teacher-students interaction in the next lesson. Due to the barrier of the time and location, the interaction of offline learning is limited to a certain extent. However, multi-dimensional interaction with the help of a variety of network platforms provides a new basis for the 
development of an online PAD (OPAD). The pattern of PAD class can be shown as follows (Fig. 1).

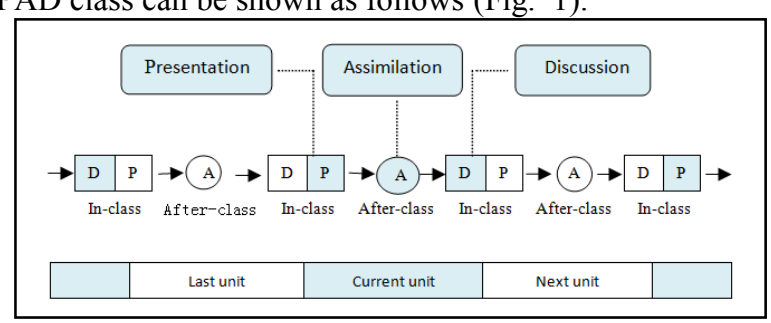

Figure 1. The pattern of PAD class.

\subsection{In-class PAD}

In the OPAD mode, in-class PAD takes place in online class time. In Unit Two of Integrated English course, when explaining the topic of "the virtues of growing older", there is a saying that Americans try their best to keep young and even sign a contract with the devil. The sentence "It is unAmerican to say so" has an ironic meaning. The teacher set up a brainstorming activity in the class of Lanmuo Cloud Class platform. After a short period of individual learning in online class, students posted their opinions on this platform and student-student interaction has been realized. They clarified most of the concepts, and then return back to the QQ platform online class. They brought their ideas and questions and had a dialogue with the teacher. We can clearly notice that interaction plays an important role in OPAD learning.

\subsection{Between-class PAD}

\subsubsection{Pre-class setting}

Teachers assign tasks in QQ online class and Lanmuo Cloud class in advance and send messages to remind students to think about relative questions before ahead of time and build their vocabulary. Grouping by themselves, students are divided into different groups to get ready to the next lesson. They also put forward their own views on the old and young, share interesting stories when they were young on the Lanmuo platform. Some students wrote questions to consolidate vocabulary memory and clarify related usages.

\subsubsection{In-class setting}

Students consolidated key words and thought about questions related to the topic through an interaction before class. The next lesson, the first session, the teacher assigns students to have a short online discussion and collect the questions from the groups. He/she picks up the questions and has a dialogue with students. After that, he/she set up a debate entitled "Being young or growing older, which one has more virtues? The teacher used the hand-raising function of the Lanmuo Cloud class platform to determine the pros and cons. Based on group discussion, students used the vocabularies to discuss and expressed their opinions, which stimulated their interests in online learning and created conditions for cultivating positive values on their life. In the second session, the teacher begins to a new topic. $\mathrm{He} / \mathrm{she}$ provides a new presentation in the second session and then student internalize their knowledge after class and another study circle will come.

\subsubsection{After-class setting}

Given after-class study is a crucial period for knowledge internalization, PAD paradigm created an after-class study pattern called "Empress Me", "Challenge You", and "Help Me". Students allow to expressing their ideas in after-class online discussion, tested for each other, and take notes for their "Help Me" questions. If the group member can solve each others' "Help Me" questions, there are no questions for the teacher in the next lesson; if students cannot solve their questions, the leader of the group will collect many "Help Me" questions to the teacher. A dialogue between students and the teacher happens again. During this study period, many interactions have been realized.

Antoro and Sudilah use group discussion to divide the whole class into several groups and set up a forum to encourage students to discuss within and between groups, thus improving the quality and quantity of interaction [11]. In this study, the online discussion groups are similar to the forum Sudilah established, which shows the effectiveness of OPAD interaction. These interactive forms enhance the participation of students and reflect the advantages of all media.

\section{QUASI-EXPERIMENTAL STUDY}

In order to observe the students' online English learning results under PAD mode, a self-made questionnaire was designed based on Likert classification of five levels. The questionnaire was divided into four dimensions: Personal feeling, Personal change, Students' attitude and Teaching design. There were 20 questions in total, including 16 forward narration questions, 4 reverse narration questions, and the last one was a short answer question, which was a supplement to multiple-choice questions. The Cronbach $\alpha$ coefficient of the questionnaire is tested, and the alpha reliability coefficient is 0.817 , which shows that the questionnaire is very reliable. The survey was conducted among 62 freshmen in two classes who participated in the online learning of Integrated English course. The experimental class (32 students) implemented PAD mode teaching and learning while the control class (30 students) used the traditional teaching method. The students in the experimental class and the control class came from different provinces in China, and there was no significant 
difference in their College Entrance Examination scores and they knew nothing about this experiment. Among the questionnaires, 32 samples were collected in the experimental class, while 30 were collected in the control class, with a recovery rate of $100 \%$.

Within the four dimensions, an independent sample t-test is conducted on the data collected to understand whether there are differences those four dimensions in the two classes under the OPAD paradigm. The P-P diagram intuitively reflects the normal distribution trend of each dimension (Fig. 2).
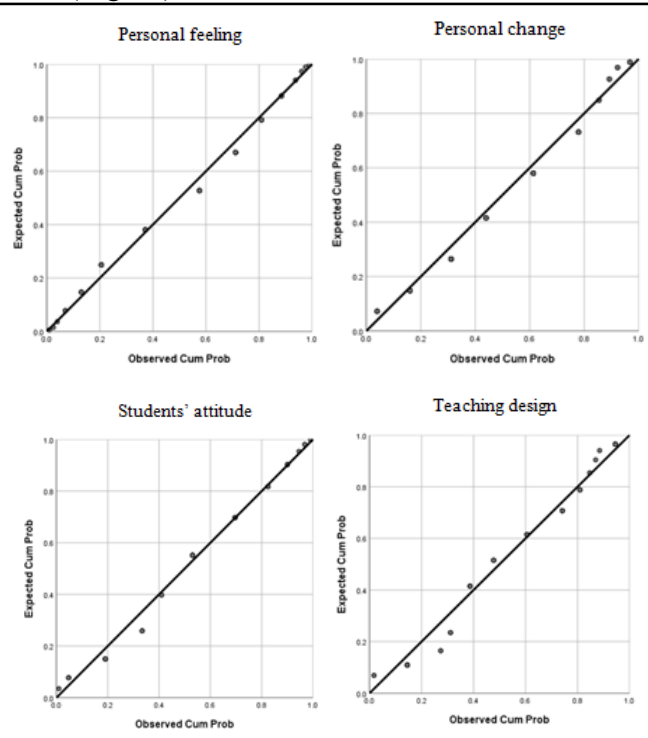

Figure 2. Normal P-P plot of the four dimensions.

The independent samples test results show that the experimental class and the control class has a significant difference $(\mathrm{P}=0.033,<0.05)$ in only the Students' attitude dimension towards online PAD mode, and there is no significant difference in other dimensions (Table 1), indicating that Students' attitude is the main influencing factor for students' participation in online learning. To understand whether there is correlation and mutual influence among the dimensions, correlation analysis was conducted on the statistical data (Table 2).

Table 1. Experimental group $(\mathrm{n}=32)$ and control group $(n=30)$ independent sample test

\begin{tabular}{|c|c|c|c|c|c|}
\hline Dimensions & Group & Mean & $\begin{array}{c}\text { Std. } \\
\text { Deviation }\end{array}$ & $\mathbf{t}$ & Sig \\
\hline \multirow{2}{*}{$\begin{array}{c}\text { Personal } \\
\text { feeling }\end{array}$} & $\begin{array}{l}\text { Experimental } \\
\text { group }\end{array}$ & 3.2250 & 0.50737 & \multirow{2}{*}{1.188} & \multirow[t]{2}{*}{0.239} \\
\hline & Control group & 3.0733 & 0.49684 & & \\
\hline \multirow{2}{*}{$\begin{array}{l}\text { Personal } \\
\text { change }\end{array}$} & $\begin{array}{l}\text { Experimental } \\
\text { group }\end{array}$ & 3.7969 & 0.56951 & \multirow[t]{2}{*}{1.925} & \multirow[t]{2}{*}{0.059} \\
\hline & Control group & 3.5083 & 0.61055 & & \\
\hline \multirow{2}{*}{$\begin{array}{l}\text { Students' } \\
\text { attitude }\end{array}$} & $\begin{array}{l}\text { Experimental } \\
\text { group }\end{array}$ & 3.6750 & 0.45931 & \multirow[t]{2}{*}{2.184} & \multirow[t]{2}{*}{$0.033^{*}$} \\
\hline & Control group & 3.4067 & 0.50782 & & \\
\hline \multirow{2}{*}{$\begin{array}{l}\text { Teaching } \\
\text { design }\end{array}$} & $\begin{array}{l}\text { Experimental } \\
\text { group }\end{array}$ & 3.9219 & 0.62768 & \multirow[t]{2}{*}{1.107} & \multirow[t]{2}{*}{0.273} \\
\hline & Control group & 3.7389 & 0.67336 & & \\
\hline
\end{tabular}

Table 2. Correlations for the four dimensions $(n=62)$

\begin{tabular}{|c|c|l|l|l|l|}
\hline Dimensions & Groups & $\begin{array}{c}\text { Personal } \\
\text { feeling }\end{array}$ & $\begin{array}{c}\text { Personal } \\
\text { change }\end{array}$ & $\begin{array}{l}\text { Students' } \\
\text { attitude }\end{array}$ & $\begin{array}{l}\text { Teaching } \\
\text { design }\end{array}$ \\
\hline \multirow{2}{*}{$\begin{array}{c}\text { Personal } \\
\text { feeling }\end{array}$} & $\begin{array}{c}\text { Pearson } \\
\text { correlation }\end{array}$ & 1 & $0.282^{*}$ & $0.331^{* *}$ & $0.188^{*}$ \\
\cline { 2 - 6 } & $\begin{array}{c}\text { Sig.(2- } \\
\text { tailed) }\end{array}$ & & 0.026 & 0.008 & 0.143 \\
\hline \multirow{2}{*}{$\begin{array}{c}\text { Personal } \\
\text { change }\end{array}$} & $\begin{array}{c}\text { Pearson } \\
\text { correlation }\end{array}$ & $0.282^{*}$ & 1 & $0.805^{* *}$ & $0.814^{* *}$ \\
\cline { 2 - 6 } & $\begin{array}{c}\text { Sig.(2- } \\
\text { tailed) }\end{array}$ & 0.026 & & 0.000 & 0.000 \\
\hline \multirow{2}{*}{$\begin{array}{c}\text { Students, } \\
\text { attitude }\end{array}$} & $\begin{array}{c}\text { Pearson } \\
\text { correlation }\end{array}$ & $0.331^{* *}$ & $0.805^{* *}$ & 1 & $0.815^{* *}$ \\
\cline { 2 - 6 } & $\begin{array}{c}\text { Sig.(2- } \\
\text { tailed) }\end{array}$ & 0.008 & 0.000 & 0.000 \\
\hline \multirow{2}{*}{$\begin{array}{c}\text { Teaching } \\
\text { design }\end{array}$} & $\begin{array}{c}\text { Pearson } \\
\text { correlation }\end{array}$ & $0.188^{*}$ & $0.814^{* *}$ & $0.815^{* *}$ & 1 \\
\cline { 2 - 6 } & $\begin{array}{c}\text { Sig.(2- } \\
\text { tailed) }\end{array}$ & 0.012 & 0.000 & 0.000 & \multicolumn{2}{|c|}{$*{ }^{* *} \leq 0.001, * \mathrm{P} \leq 0.05}$. \\
\hline
\end{tabular}

Correlation analysis shows that Personal feeling, Personal change, Students' attitude and Teaching design are significantly correlated, and Personal change has a higher level of correlation with Personal feeling, Students' attitude and Teaching design (Table 2). Further regression analysis showed that personal change (Y) was taken as the dependent variable, Personal feeling (X1), Students' attitude (X2) and Teaching design (X3) was taken as the independent variables to conduct multiple regression analysis, and the multiple regression equation was obtained: $\mathrm{Y}=0.036+0.074 \mathrm{X} 1+0.469 \mathrm{X} 2+0.450 \mathrm{X} 3(\mathrm{R} 2=0.711$, $\mathrm{F}=51.105)$. The regression coefficient values were shown in Table 3.

Table 3. Coefficients

\begin{tabular}{|c|c|c|c|c|c|}
\hline Dimensions & B & $t$ & Sig & $\mathbf{F}$ & $\mathbf{R}^{2}$ \\
\hline Constant & 0.036 & 0.104 & 0.917 & \multirow{4}{*}{51.105} & \multirow{4}{*}{0.711} \\
\hline Personal feeling & 0.074 & 0.838 & 0.406 & & \\
\hline Students' attitude & 0.469 & 3.101 & * 0.003 & & \\
\hline Teaching design & 0.450 & 4.052 & $\begin{array}{l}0.000 \\
* *\end{array}$ & & \\
\hline
\end{tabular}

It shows that the regression coefficient of Students' attitude is $0.469(\mathrm{P}=0.003,<0.01)$, which has the biggest contribution to the regression equation. The second contributor is Teaching design, with the coefficient 0.450 $(\mathrm{P}=0.000,<0.001)$, which has the greater significance than the factor of Students' attitude. Within the three factors, the coefficient of Personal feeling is $0.074(\mathrm{P}=0.406,>0.01)$, which has little significant contribution to the dimension of Personal change, so it should not enter into the equation.

\section{RESULTS}

The change of students' learning behavior depends on many factors. First, teaching design is the key factor contributing to students' behavior changes. By using OPAD mode, the teacher designed a lot of activities involving students in discussion so that students could share learning opinions and did not feel lonely while learning. Second, from the independent sample test, we can clearly see that students' attitudes in experimental group have higher score than that of control group, showing that attitudes plays a key role in the effect of online learning. Third, Personal change has a higher level of correlation with Students' attitude and Teaching design, showing that 
these factors intertwine together to function. Personal feeling is also related to learning behavior and should be considered as one of the factors, though it has little contribution to the regression equation.

\section{DISCUSSION}

First of all, teaching design plays a key role in the effect of online learning. Teaching design is a series of processes in which teachers systematically analyze the various elements of the teaching system with a systematic method to optimize the teaching effect as the starting point and ultimate goal, and then carry out scientific planning accordingly. In online teaching, teaching design should not only include teaching content, teaching objectives, teaching organization form and other aspects, but also pay attention to the conditions and environment of the media used, and select appropriate methods to organize teaching and carry out activities. The interactive teaching under the PAD paradigm adopted in this study is exactly what students like and are willing to try. For example, brainstorming in class, expressing one's views in different time and location, taking into account the understanding of discourse meaning, vocabulary practice and cultural exploration are all typical activities. In this way, interaction design plays a positive role in arousing interest, maintaining learning desire and overcoming the adverse effects of online learning. This result is consistent with the one proposed by Wang and Tian that $70 \%$ of students in the multimodal interactive teaching think that student-to-teacher interaction and group interaction have a promoting effect on learning results[13]. And it is also consistent with the research abroad that teachers should pay more attention to the design of online teaching content to attract more attention from students [14]. Therefore, teachers' online teaching design is one of the key elements to attract students to participate in classroom activities and achieve the goal of online teaching. Second, attitudes play a very important role in the effect of online learning. Attitudes refer to a person's likes or dislikes towards an object, as well as his reaction tendency towards this object. Attitudes provide information for specific behavior reactions and enable a person to make the right decision, that is, to seek advantages and avoid disadvantages, and also to express the value of a person. Therefore, when people think that network teaching is a strange learning method out of the habit which is boring, consumes more energy and lacks of interaction and communication, they will show no interest, and will not involve themselves in learning. So the resistance to learning will increase and the effect of learning will be greatly reduced.

Third, personal feeling is also related to learning behavior and should be considered as one of the factors. If the teaching design is attractive enough to students, provides more technical and emotional support, reduces cognitive load, and makes students feel more humanized, learning outcomes and goals will be easily achieved.

Besides, the experimental class carried out multidimensional interaction under the OPAD paradigm, which is a new attempt for students. For example, in between-class PAD, through pre-class vocabulary preparation, in-class debate activities and after-class storytelling, students will have abundant opportunities to experience online learning and form the understanding that online activities can also realize multiple offline activities. So the students will overcome the strangeness of online learning and change their attitude and actively engage in online activities. The usability, ease of use and content design of online learning are the main factors that influence learners' attitude towards online learning. Between-class in the PAD paradigm enables students to experience the convenience, richness and interest of online learning. In this way, students will ignore the discomfort of online teaching, change their attitude and behavior, and achieve the goal of learning.

\section{CONCLUSION}

This study focuses students' online learning behavior changes based on PAD mode. This mode can better capture students' attention and make teaching more effective. The OPAD interactive instructional focuses more on the learning process of students, pays attention to the learning experience, and encourages students to express their attitudes by group discussions and other activities in online learning, thus changing their learning behaviors.

The following enlightenment can be drawn. (1) Teachers should first make good use of network platforms to support students to have discussion on these platforms. (2) To have a good design in online teaching, practice interactive strategy, and try hard to make the online teaching similar to that of offline teaching is what front-line teachers should do. (3) Students should overcome the discomfort of online learning and actively engage in the interactive process of learning, to gain greater results.

In short, both teachers and students should actively learn new teaching concepts and methods, equip their minds with advanced science and technology, change outdated concepts and habits, and embrace the revolution of technology and education with an open mind. Only in this way can they enjoy and make use of the achievements brought by the development of technology. Further research will be carried out to find out more valuable experience for online teaching and combined online and offline teaching.

\section{ACKNOWLEDGMENT}

The authors acknowledge the Thirteenth Five-Year Plan of Shaanxi Province Education Science Project of 2020 "Study on the English Learning Process of ApplicationOriented University Students Based on the Paradigm of PAD”, Project No. SGH20Y1475. 


\section{REFERENCES}

[1]Maskun, T. Rusman, Suroto, and F. Rahmawati, "Student Perceptions of Online Learning," J. International Journal of Multicultural and Multireligious Understanding, 2020, vol. 7, pp. 67-73. DOI: http://dx.doi.org/10.18415/ijmmu.v7i2.1416

[2]M. Cao, "Mulit-dimensional Interaction in online PAD class--Taking the course of integrated English as an Example," J. Testing and Evaluation (college English Teaching \& Research), Beijing: 2020, Issue 5, pp.68-73. (In Chinese)

[3]X. Ma, J. Liang, X. Li, and Y. Su, “An empirical study on the effect of group perception on online collaborative learning," J. e-Education Research, Lanzhou. China, 2019, Issue 5, pp. 81-89. DOI: 10.13811/j.cnki.eer.2019.05.011 (In Chinese)

[4]J. R. Buelow, T. Barry, and L. E. Rich, "Supporting learning engagement with online students," J. Online Learning, 2018, vol. 22, pp.313-340.

DOI:10.24059/olj.v22i4.1384

[5]M. Cao, "Design and implementation of multidimensional interaction in online English course under the assistance of omnimedia," J. Scientific Programming, Vol. 2021, pp. 1-10. DOI: https://doi.org/10.1155/2021/3713161

[6]A. Yulia, N. A. Husin, and F. I. Anuar, "Channeling assessments in English language learning via interactive online platforms," J. Studies in English Language and education, 2019, vol. 6, pp. 228-238. DOI: https://doi.org/10.24815/siele.v6i2.14103

[7]X. X. Zhang, "PAD class:A new attempt in university teaching reform," J. Fudan Education Forum, Shanghai. China, 2014, vol.12, pp. 5-10. DOI: 10.13397/j.cnki.fef.2014.05.002 (In Chinese)
[8]J. Feng, X. Zhou, and J. Li, "The application of the Presentation-Assimilation-Discussion class in pharmacology for nursing undergraduates," J. Chinese Journal of Nursing Education, Beijing. China, 2021, Issue 1, pp. 45-49. DOI:10.3761/j.issn.16729234.2021.01.009 (In Chinese)

[9]G. M. Moore, "Editorial: Three types of interaction," J. American Journal of Distance Education, 1989, vol. 3, pp. 1-7. DOI: $10.1080 / 08923648909526659$

[10] S. Mehall, "Purposeful interpersonal interaction in online learning: What is it and how is it measured?" J. Online Learning, 2020, vol. 24, DOI: https://doi.org/10.24059/olj.v24i1.2002.

[11]S. D. Antoro, and Sudilah, "Enhancing learning interaction through inter-forum group discussion in online learning: A case study on online teaching of research in English language teaching course," J. Ahmad Dahlan Journal of English Studies, 2016, Vol. 3, pp. 64-82.

[12]H. Li, and Y. T. Wei, Research on the Construction and Application of Learning Behavior Evaluation System in Hybrid Teaching. China Educational Technology, 2020, Issue 10, pp. 58-66. (In Chinese)

[13]X. M. Wang, and Y. Tian, "An empirical study on multimodal interactive college English teaching," J. Heilongjiang Researches on Higher Education, 2020, Issue 1, pp. 152-156. (In Chinese)

[14]M. Jović, M. K. Stanković, and E. Nešković, "Factors affecting students' attitudes towards elearning.," J. Management: Journal of Sustainable Business and Management Solutions in Emerging Economies, 2017, vol. 22, pp. 73-80. DOI: 10.7595/management.fon.2017.0016 